\title{
Las huellas del canal de Cabarrús en el siglo XXI: evolución de la gran empresa ilustrada de la cuenca del Jarama (1767-2019)
}

Eva Niño Mendizábal ${ }^{a}$, Elia San Román Vázquez ${ }^{a}$

${ }^{\mathrm{a}}$ Mainel arquitectura, c/Zazuar nº, 28031, Madrid, info@mainelarquitectura.com

\begin{abstract}
Resumen
Este artículo aborda un análisis de las construcciones e instalaciones que formaron parte de la gran empresa constructiva del Conde de Cabarrús a finales del s. XVIII, así como de las restauraciones llevadas a cabo en los últimos años. Entre estas construcciones se pueden encontrar a día de hoy, aparte del trazado parcial del propio canal, los restos de pontones, acueductos, presas, molinos, y casas de guarda y almacenaje.

A comienzos del s.XXI, la mayor parte de estas construcciones habian desaparecido o se encontraban en estado de ruina. Sin embargo, el mayor problema era que se encontraban desligadas del contexto paisajístico en el que se habian construido, ya que la mayor parte del trazado de este canal, elemento referencial de todas ellas, se había perdido. En la última década se han realizado distintas intervenciones a cargo de diferentes equipos técnicos, siguiendo una metodología común, con el objetivo de volver a poner en contexto a cada uno de estos elementos, recuperando en la medida de lo posible las trazas del Canal y la integridad material de sus construcciones.
\end{abstract}

Palabras clave: canal, puente, acueducto, siglo XVIII, Lemaur, Canal de Isabel II, patologías, piedra, restauración.

\begin{abstract}
This article deals with an analysis of the constructions and facilities that were part of the great infrastructure carried out at the end of the 18th century by the Count of Cabarrus, from whom it bears his name, as well as the restorations carried out in recent years. Among these constructions it can find today, apart from the partial layout of the canal itself, the remains of pontoons, aqueducts, dams, mills, and guard and storage houses.

At the beginning of the 21st century, most of these constructions had disappeared or were in a state of ruin. However, the biggest problem was that they were detached from the landscape context in which they had been built, since most of the route of this canal, a reference element of all of them, had been lost. In the last decade, different interventions have been carried out by different technical teams, following a common methodology, with the aim of putting each of these elements back into context, recovering as far as possible the traces of the Canal and the material integrity of its constructions.
\end{abstract}

Keywords: canal, bridge, aqueduct, 18th century, Lemaur, Canal de Isabel II, pathologies, stone, restoration. 


\section{Introducción}

El canal de Cabarrús se sitúa en el noreste de la Comunidad de Madrid. El objeto de la construcción de este canal era canalizar las aguas del Lozoya para generar una red de abastecimiento para las huertas de la Vega del Jarama, así como facilitar el transporte de mercancías. El trazado comenzaba en el término municipal de Patones de abajo, y discurría por las poblaciones de Torremocha de Jarama y Torrelaguna para finalizar en la Granja de Caraquiz situada en las orillas del río Jarama. A su paso tuvo que sortear caminos, arroyos, y desniveles, así como controlar el caudal de sus aguas y repartirlas, hechos que generaron un interesantísimo conjunto arquitectónico de pontones, presas, acueductos, molinos, caces, y casonas con distintos grados de conservación y algunos de ellos todavía en uso.

\section{El trazado histórico}

Según el estudio histórico llevado a cabo por Gonzalo López-Muñiz (López-Muñiz, 2015), ya debían existir en la vega del Jarama una acequia, y un molino desde la Edad Media. En el s. XVII se construyó la famosa presa de la Guesa (Espinosa, 2001). Cuando Francisco Echauz adquiere los derechos de las aguas del caz en 1767, la presa se encuentra destruida. Echauz contrató al arquitecto Vicente Fornells para ampliar el trazado del caz existente, comenzándose la construcción de pontones, molinos y una gran presa (Martín y Prieto, 1988). Se sabe que las obras llegaron hasta el arroyo de San Román y constituyeron la base del futuro trazado del Canal de Cabarrús (López, 1986).

Tras múltiples pleitos con los diezmeros, sabotajes, problemas técnicos y económicos, la heredera de Pedro y Francisco Echauz vende en 1796 el canal y sus derechos al Conde de Cabarrús. Francisco de Cabarrús Lalanne (1752-1810) fue un economista, financiero y político afrancesado de ideas ilustradas. Cabarrús fue también el promotor de ambiciosas empresas, tales como La real Compañía de Filipinas o el Canal objeto de este artículo.

El proyecto corrió a cargo de los hermanos Francisco y Carlos Lemaur, ingenieros franceses hijos de Carlos Lemaur, autor del proyecto del canal de Canal de Castilla. Los Lemaur no sólo pretendían regar las huertas de la vega y cobrar diezmos por el agua, sino que querían crear una zona productiva a lo largo de todo el canal que, además, debía de ser navegable para poder de esta manera dar salida al excedente de producción (Candela, 2009). Para ello aumentaron tanto el ancho como el recorrido del canal construido por Echauz. Tal como podemos observar en el plano topográfico de 1851 (Fig. 1), el canal tenía en origen tres tramos bien diferenciados: El primero, desde el puente de la Oliva hasta el acueducto de la cerrada; El segundo desde este primer acueducto hasta el acueducto de San Román, y el tercero entre el acueducto de San Román y el río Jarama.

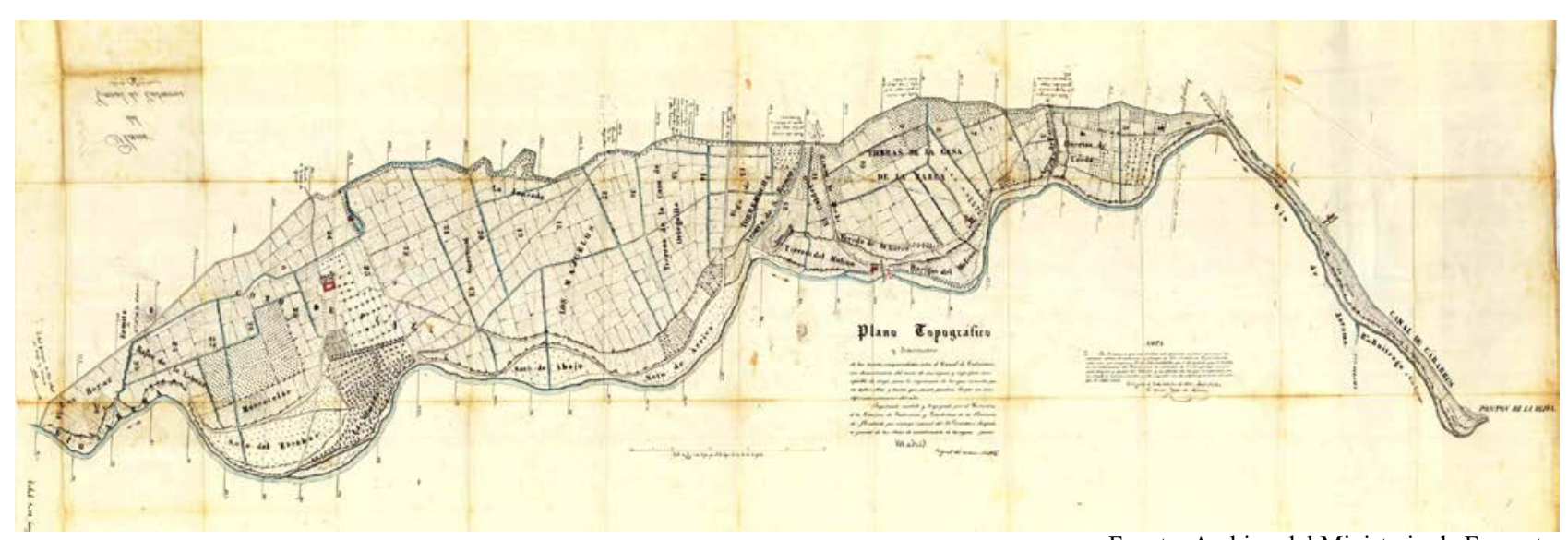

Fuente: Archivo del Ministerio de Fomento

Fig. 1 Plano topográfico de la Vega de Uceda regada por el Canal de Cabarrús. Año 1851. Ingeniero Josef Nieto

El primer tramo fue el primero en construirse y es además el que presenta mejor estado de conservación, ya que de hecho actualmente se conserva en uso parte de su trazado. En este primer tramo destacan la existencia de varias casas de guarda, el acueducto de la cerrada y un pontón situado cerca del mismo. El segundo tramo del canal desapareció durante el s. XX debido al paso de una carretera, pero se tiene constancia de que estuvo en uso hasta finales del siglo XIX. 
Tenía una pendiente menos acentuada y una mayor anchura del caz. Su trazado está jalonado por varias casas de guarda, varios pontones, y el acueducto de San Román, obra hidráulica principal del proyecto y cuya restauración se detallará en este artículo. El tercer tramo probablemente no fue concluido en su totalidad. Existían varios caces, dando uno de ellos servicio al molino de la casa de oficios. En este tramo se edificaron las casas de colonos en las que se alojaron a los agricultores provenientes de levante, y existen al igual que en los otros dos tramos restos de varios pontones y casas de guarda.

Existe la posibilidad de que este canal fuera navegable. En una carta datada el 21 de febrero de 1797 se menciona dicha posibilidad. Al explicar al Conde el origen de diversos gastos y sobrecostes producidos en la obra, los ingenieros indican el aumento de precio de ejecución de cada puente construido hasta la fecha "por haver dado mas alturas a los puentes a fin de que la Azequia pueda ser tambien navegable" (López-Muñiz, 2015). Este testimonio de los propios ingenieros revela sin duda su intención de abrir un Canal navegable aprovechando el trazado de Echauz. Otra carta del 17 de mayo de 1798 escrita por los hermanos Lemaur al Conde contiene varias contestaciones a preguntas específicas realizadas por Cabarrús. El Conde se había quejado de que le hubiesen prometido que el canal podría ser navegable, ya que era una condición que no iba a tener nunca, debido a que su elevada pendiente impedía un caudal suficiente de aguas para la navegación. Los ingenieros contestaron entonces que el objetivo principal era el riego, y este se cumplía con creces. Explican que la navegación era posible aguas abajo y que en el resto de los tramos no era imposible. Quedaba entonces garantizada la navegación entre el $1^{\circ}$ acueducto y el paraje destinado a la casa y el molino. Todavía en 1799-1801 hay relaciones de pagos para intentar hacer más navegable el canal mediante la construcción de un barco específico y la intervención en algunos de los puentes.

En septiembre de 1797 las obras ya habían llegado a la altura de la Casa de Oficios (3º tramo). En mayo de 1798 las obras habían concluido, y se estaban realizando tareas de reparación y mantenimiento, aunque las construcciones accesorias como casas de guardas y molinos estaban todavía en proceso de construcción (López, 1986). En los primeros años del s. XIX las tierras ya producían varios cultivos. Durante la guerra de Independencia (1808-1814) el número de diezmeros de reduce a veinte, produciéndose un cierto abandono de las instalaciones.

Tras la muerte del Conde en 1810 se abre un proceso judicial. Su adhesión al bando de José Bonaparte supuso la expropiación de sus bienes tras la guerra quedando bajo una administración judicial que gobierna el canal hasta mediados de la década de 1850. La administración hizo en 1817 un completo inventario de todas las posesiones expropiadas donde se detallan los diferentes tramos del canal y los cultivos. A finales de la década de 1820 las propiedades regadas por el Canal sufrieron un proceso de división que conllevó el aumento de los diezmeros, pasando a sumar ciento dieciseis. En este periodo se realizan diversas obras, como el "bocal de Caraquiz" y varios trabajos de mantenimiento (López, 1995).

En la década de 1820 se producen varios altercados en la Vega de Uceda afectando a la familia Cabarrús que en esos años estaba bajo tutela judicial. Se produjeron varios robos y destrozos en las construcciones accesorias, cultivos y en el propio canal. Los vecinos de Torrelaguna enumeran los daños en 1820 "Han quemado las casas, las han destejado, se han llevado puertas y ventanas; reunidos y armadas en cuadrillas han apaleado a los Guardas cuando han querido oponerse a sus robos; $y$ en fin ha llegado el caso que el propietario vea asolada diariamente su propiedad y haya sufrido en silencio y resignado. Aquel establecimiento modelo de la agricultura en grande, no presenta en el día sino la imagen de la destrucción". (López-Muñiz, 2015).

Entre 1848 y 1851 Se realizan las últimas grandes obras de reparación del canal. El canal presentaba cuatro o cinco roturas importantes en el tramo que va desde la presa hasta la casa almacén. El ingeniero Mariano Donaire realiza en diciembre de 1848 un reconocimiento del trazado. En su informe indica que en el primer bocal faltaban las compuertas y en toda la línea que discurría por debajo del cerro de "Las Calerizas" había localizado un total de cincuenta y una roturas "de muchisima consideración muchas de ellas, por las cuales es capaz de marcharse doble de Caudal de agua que las que ordinariamente conduce este Canal”. En opinión de Donaire las causas de estas roturas eran que el Canal estaba "construido sobre una solapa de piedra caliza vertical del Cerro al rio, sobre la cual pasa el Canal sobrepuesto de tierra y estando minado de los topos y del grande abandono en que debe haber estado por muchos años”. (López- 
Muñiz, 2015). Era por lo tanto necesario macizar estas roturas con cal hidráulica y consolidar el terreno sobre el que discurría el Canal con hormigonado que también se emplearía para la plataforma del caz.

En esta época el canal se encuentra dentro de un entorno de pleitos y desavenencias que provenía ya de los tiempos en que el Conde y los hermanos Lemaur estaban vivos. Estos hechos son la principal causa de la ruina del canal. Las riñas y tensiones entre los Cabarrús y los Lemaur continuaron hasta finales del s. XIX. Tras la disolución de la sociedad en 1799 los propietarios y regantes subarrendaron las fincas a precios tan bajos que no llegaban siquiera para cubrir los diezmos. Los pleitos continúan con los herederos de ambos socios. El proceso se dilató hasta el año 1855 cuando se dictó nueva sentencia favorable a la familia Cabarrús. La actitud de Cabarrús, de los colonos y de los regantes fue sin duda un factor importante en la ruina del proyecto. Pero el verdadero motivo del descalabro de la empresa fue el punto de partida, con unos cálculos y unas previsiones de explotación absolutamente irreales e imposibles de alcanzar. Además, el mantenimiento de una obra tan costosa como el Canal era un gasto que también fue presupuestado muy a la baja por los ingenieros Lemaur en su propuesta inicial.

La construcción del Canal de Isabel II y su presa del actual Pontón de la Oliva, supuso el fin de la propiedad de la familia Cabarrús, al ser expropiado el Canal después de un largo proceso administrativo y judicial que finalizó en el año 1879. En junio de 1880 el Estado toma posesión de las dependencias. Esta expropiación afectó en gran medida a las instalaciones ya que desde un primer momento se extrajo sillería labrada para el acto de inauguración de la Presa del Pontón, para la nueva casilla construida al lado de la del guarda del Pontón y para el parapeto levantado en sus costados.

En 1880 se realiza un informe detallando la viabilidad de su posible puesta en funcionamiento y las obras necesarias en el mismo. Este informe es de gran interés histórico, no sólo porque permite conocer el estado real del Canal en ese momento, sino también porque aporta una serie de dibujos y croquis del Canal y de todas las obras de fábrica existentes. El informe concluyó que el estado del canal era de completo abandono y no era posible explotarlo de forma que compensaran los gastos de las obras. El tramo más afectado era el que se extendía desde el Pontón de la Oliva hasta el arroyo de las Cuevas. Por último, se estimó que el trecho de Canal con solera y cajero de mampostería era utilizable (primer tramo). En el año 1908 la Dirección del Canal de Isabel II mostró de nuevo interés por recuperar el antiguo Canal de Cabarrús, lo que se tradujo en la redacción de un Nuevo informe de gestión y de un proyecto de reparación del Canal (Orduña, 1925). El estado general del Canal era malo y sólo era útil en una longitud de poco más de cinco kilómetros correspondientes con el tramo comprendido entre el Pontón de la Oliva y el paraje de La Cerrada. En cuanto a las obras de fábrica, se menciona que desde la Casa de La Cerrada hasta el final del Canal, la mayor parte estaban destruidas y las restantes se hallaban en mal estado. El Canal nunca recuperó su antigua traza ni retomó la plena actividad, manteniéndose abierto únicamente su primer tramo, tal y como se había establecido por la Dirección del Canal de Isabel II en el año 1891.

En el año 1922 la Diputación Provincial de Madrid manda la construcción de una nueva carretera provincial que unía la carretera de Torrelaguna con el Puente de Uceda, pasando por el casco urbano de Torremocha del Jarama. Este hecho es de gran relevancia, ya que arruina por completo el canal desde el Segundo acueducto (de San Román) (López, 1995). La carretera, construida finalmente en 1934, pasa sobre el canal, realizando grandes movimientos de tierras, inutilizándolo, y eliminando gran parte de los restos del trazado histórico. Aún así, el primer tramo ha continuado en funcionamiento hasta la actualidad.

\section{Construcciones}

\subsection{Construcciones auxiliares}

A lo largo del canal se construyeron numerosos pequeños caces y construcciones auxiliares para el control del caudal y la utilización de su energía. Caben destacar dos molinos: el molino del Dique (1817-1851) (Fig. 2) del cual se conservan amplias referencias documentales y planimétricas y que estuvo en funcionamiento hasta 1880 , y el molino del Polvo o de Cabarrús, situado cerca del Puente de la Oliva, del cuál sólo se sabe que fue construido a la vez que el canal. Junto a estos molinos solía haber alguna casa de guarda, almacén y cuadras. 


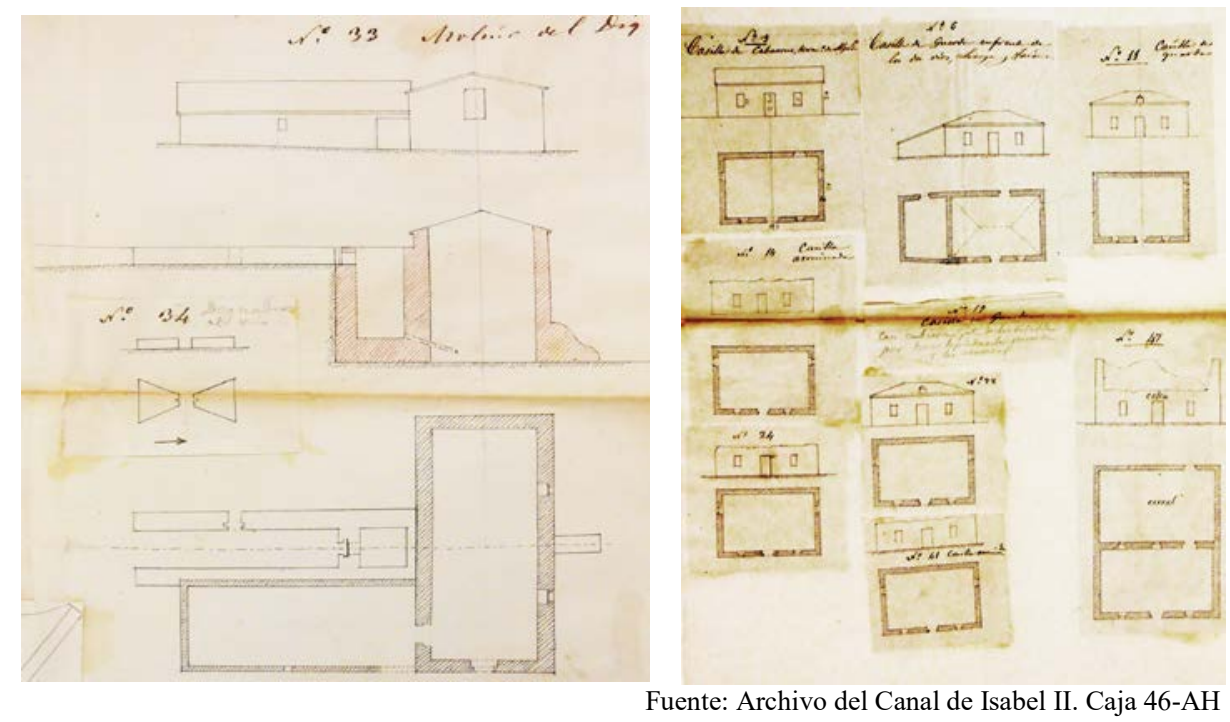

Fig. 2 Detalle del Molino del Dique y planos de las casas de guarda. Año 1880

\subsection{Edificios}

Se construyeron varios edificios para la administración y desarrollo de la actividad del canal. Entre ellos destacaba la Casa de oficios, edificio levantado entre 1798-1800 por el Conde de Cabarrús como sede administrativa de sus propiedades en la Vega de Uceda. En esta Casa se almacenaban el grano y los frutos procedentes de la explotación de la Vega y del cobro de los diezmos. También guardaban las herramientas necesarias para el trabajo en los campos y para la reparación del Canal, y contaba con una bodega.

Se construyeron también 8 casas de guarda (Fig. 2) de menor entidad cerca de pontones y pasos donde vivían los guardas encargados del control de las compuertas. A veces se acompañaban de cuadras o almacenes. Actualmente se encuentran casi todas en estado de ruina. Se sabe de la existencia de varias casas de colonos en la finca de Caraquiz construidas entre 1798 y 1803, de las cuales no conocemos exactamente su ubicación. En ellas vivían los colonos levantinos contratados para sacar adelante la producción agrícola y los encargados de ejecutar las obras.

\subsection{Pontones y acueductos}

Los pontones y acueductos fueron construidos desde el comienzo de las obras del Canal en 1797. Todos los ellos tienen la misma tipología constructiva (Fig. 3): son de un solo ojo construidos en mampostería y sillarejo bien aparejado en estribos y bóveda de piedra caliza. En la tasación de Mariategui de 1830 se contabilizaron los siguientes pontones y acueductos:

- Cerca de la presa de la Oliva, un puente de paso de 13 pies de ancho y 7 de alto

- Pontón arroyo Valdehontales (Del Hocino?): 6 pies ancho y 10 pies alto

- Pontón de paso en el arroyo cuevas, cerca de la casa- almacén de 13,5 pies alto y 8,5 pies ancho

- Pontón arroyo patones: 21 pies alto y 6 pies ancho $\left(1^{\circ}\right.$ ACUEDUCTO $)$

- Puente calle de los diezmos junto a puente arroyo patones

- Puente de casa quemada para salvar el camino de Uceda de 13 pies de ancho y 8 pies de alto

- Puente de San Román sobre el arroyo San Román de 21 pies alto y 6,5 pies ancho (2 ${ }^{\circ}$ ACUEDUCTO)

- Pontón de 13 pies de alto y 6 pies de ancho para acceder campos de labor (Paseo Jose María Oñate) (Pontón de Cambroneros)

- Pontón similar al anterior de 13 pies de anchura y 7,5 pies de alto para acceder a los campos de labor (Camino del Soto) (Puente de Majuelos)

- Pontón del camino de la casa de oficios 8 pies alto y 3 pies ancho 
- Pontón de 8 pies de alto 3 pies de ancho siguiendo el caz que daba servicio al molino para el acceso a la casa de oficios

- Pontón Santa María de la Cabeza

Actualmente quedan cinco puentes y dos acueductos. Al variar el trazado de los caminos todos ellos han perdido su función original.

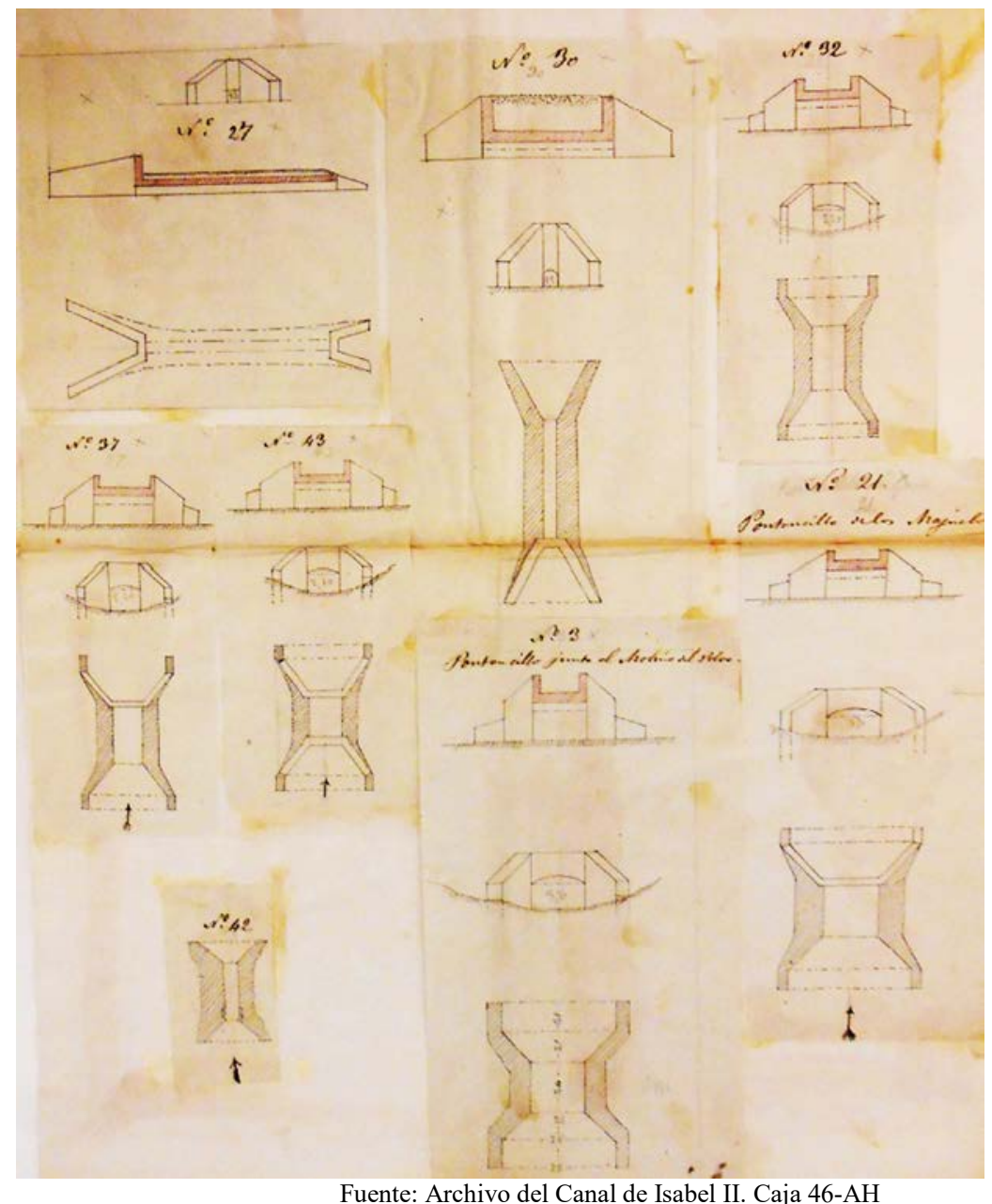

Fig. 3 Croquis de los pontones existentes en el Canal de Cabarrús. Año 1880

\section{Intervención en el acueducto de San Román ( $2^{\circ}$ acueducto)}

El primer acueducto, en Patones, es el de la "Cerrada" y el segundo es el de "San Román". Ambos responden a la misma tipología. Bajo ellos pasa un arroyo, y sobre ellos discurría el canal. Sorprende la gran anchura y profundidad que tenía el cauce ( $1 \mathrm{~m}$ de profundidad aproximada y casi $5 \mathrm{~m}$ de anchura), dimensiones que habrían permitido el paso de barcazas. Son de gran porte (cerca de $7 \mathrm{~m}$ de altura a la parte superior del pretil desde el cauce de los arroyos. Y cerca de $5 \mathrm{~m}$ de diámetro de la bóveda de cañón. Ambos han perdido su función original.

El acueducto de San Román, está en proceso de restauración a cargo del estudio Mainel Arquitectura por encargo de la Subdirección de Patrimonio de la Comunidad de Madrid que está llevando a cabo la restauración de todos los elementos del canal siguiendo los mismos criterios. Al desaparecer el eje vertebrador que suponía el canal, las construcciones existentes han perdido su contexto. En el caso de este acueducto, el curso del agua fue tapado por una carretera por la que a diario pasan vehículos pesados. Este hecho es determinante en la deformación y deterioro progresivo de la bóveda y los muros. A esto se añade el hecho de que visualmente se encuentra escondido bajo la vegetación y es imperceptible su existencia desde la carretera (Fig. 4). 


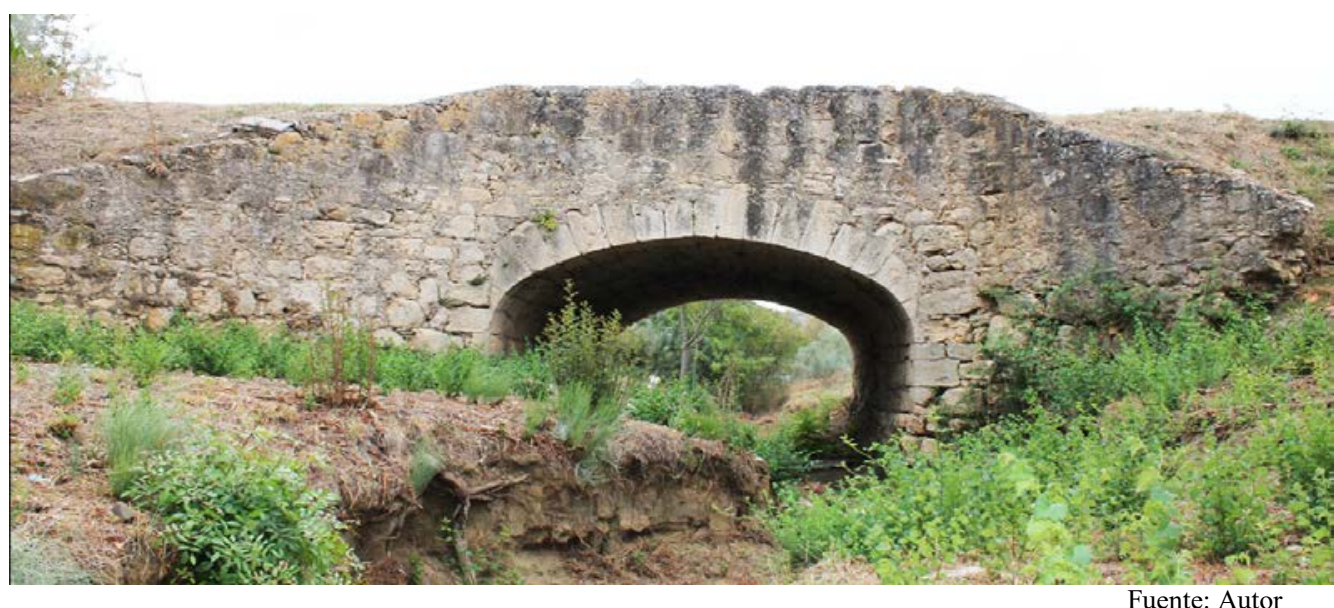

Fig. 4 Ortofoto del alzado Noroeste

Para llevar a cabo la intervención, se realizó un profundo análisis patológico del bien. Para ello hemos basado nuestro trabajo en el glosario del ICOMOS, que estudia las formas de deterioro de la piedra (Verges, 2008).

El primer grado de clasificación que realiza el ICOMOS se divide en:

- Grietas y deformaciones

- Desprendimiento

- Rasgos inducidos por pérdida de material

- Alteración cromática y depósito

- Colonización biológica

Estas lesiones han sido reunidas de forma sencilla y visual en dos tipos de fichas (Fig. 5):

- Fichas por tramo: en este caso se muestran las patologías de cada alzado identificándolas gráficamente y con una nomenclatura alfanumérica.

- Fichas por lesiones donde se cuenta su localización, qué tipo son, cómo se identifican, en qué elemento constructivo están y la descripción exacta del daño en cada parte del acueducto.

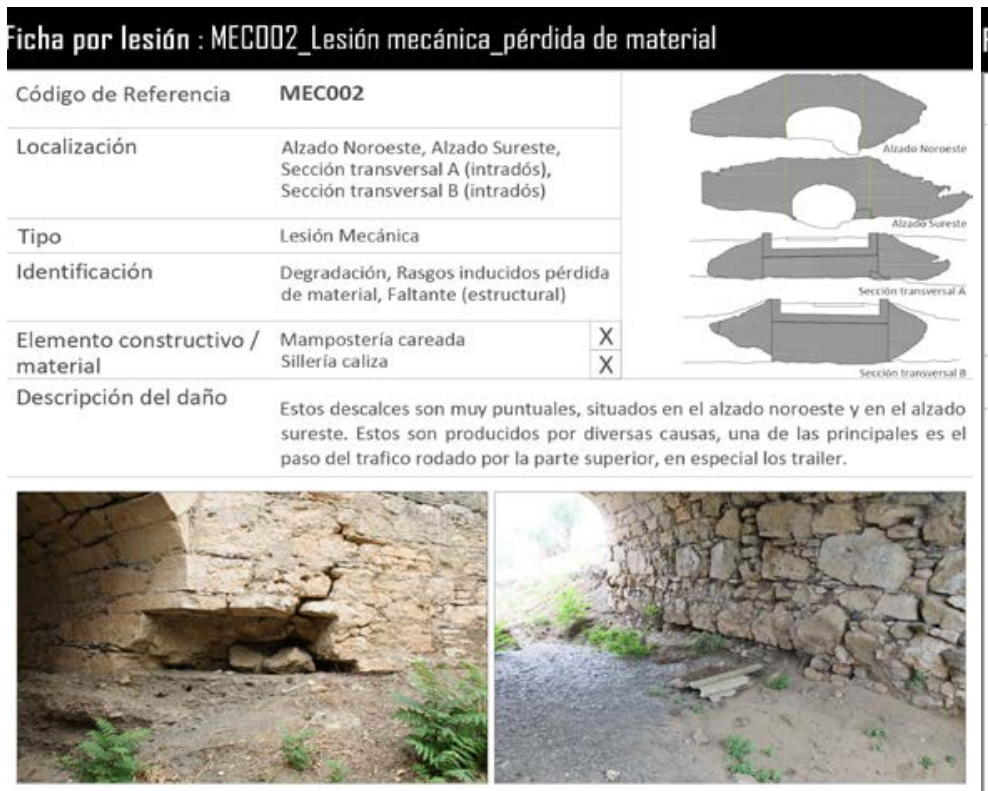

Ficha por tramo: Alzado sureste

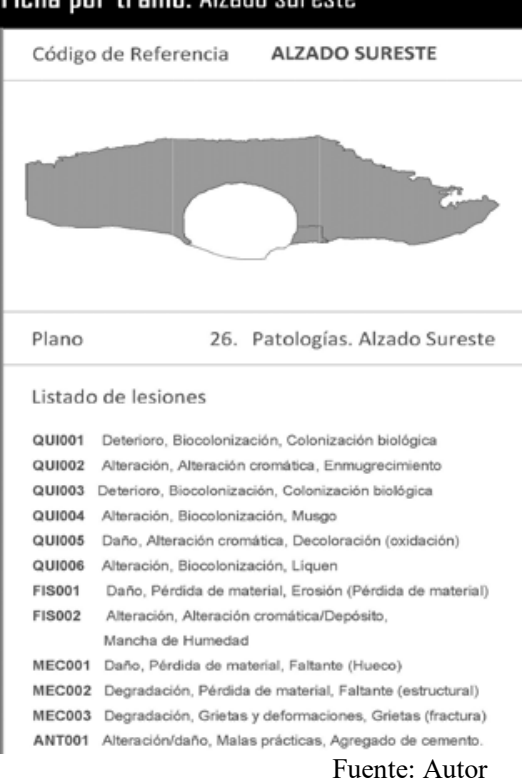

Fig. 5 Ejemplos de fichas realizadas: por lesión y por tramo 
Tras el levantamiento fotogramétrico, se realiza el análisis de cada alzado mediante un mapeado (Fig. 6), siempre siguiendo la nomenclatura dispuesta en las fichas anteriores y dividiendo la leyenda en: Lesiones físicas, Lesiones químicas, Lesiones mecánicas, Lesiones antrópicas. De esta manera se observan de forma generalizada y en conjunto las lesiones, pudiendo evaluar el conjunto de procesos patológicos que se desarrollan en el bien.

Este acueducto presenta lesiones muy similares a las del acueducto de la cerrada, aunque en este caso existen algunas lesiones características, tales como los descalces pronunciados en ambos alzados de la cimentación, y el desplome de la bóveda causada por el paso del tráfico rodado, produciendo un giro de la fachada noroeste. También es destacable la alteración cromática de las fachadas debido a la escorrentía superficial del agua.

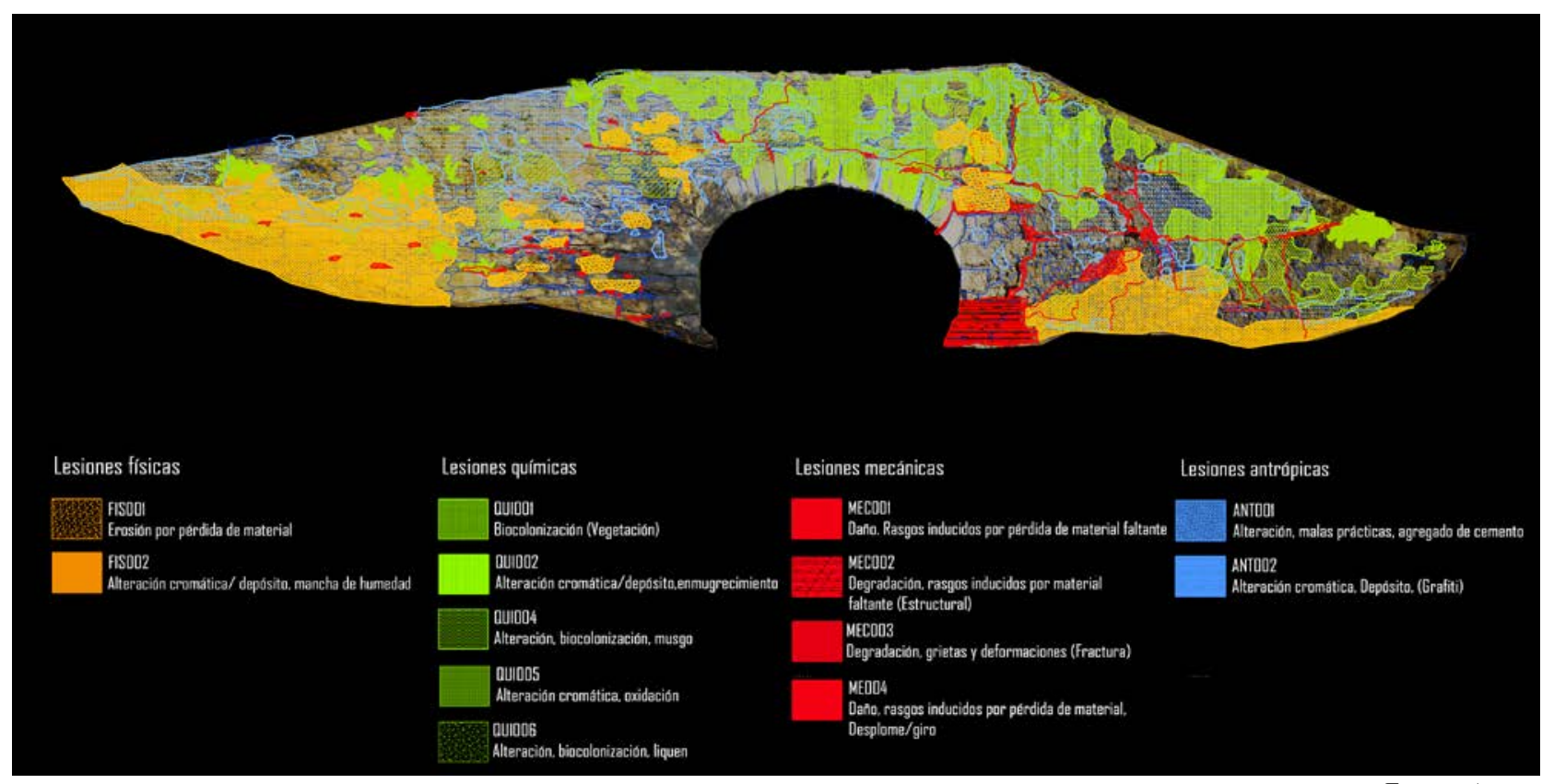

Fuente: Autor

Fig. 6 Mapeado de lesiones sobre ortofoto del alzado sureste

Una vez realizado el análisis patológico del bien, se llevaron a cabo las siguientes actuaciones:

- RESTAURACIÓN de los elementos materiales existentes. Se realizará una limpieza de la piedra mediante técnicas no agresivas, eliminación de elementos vegetales, eliminación de mortero de cemento, y rejuntado con mortero de cal similar al original.

- RECONSTRUCCIÓN con las técnicas originales los pretiles y partes faltantes significativas para su correcta comprensión. Reposición de los grandes sillares perdidos en el descalce de la cimentación del lado sureste.

- INTERVENCIÓN EN EL TABLERO Y EVACUACIÓN DE AGUAS para evitar el avance de las lesiones mediante la impermeabilización y una correcta red de drenaje. Se realizará también un correcto soporte para la carretera que reparta las cargas de forma uniforme para evitar daños sucesivos en la bóveda, a la vez que se creará una zona de paso peatonal con un adoquinado que permita la correcta filtración de las aguas hacia la red de drenaje propuesta.

- INTEGRACIÓN paisajística con el entorno del canal y los distintos elementos constructivos que lo acompañan, mediante plataformas estanciales con carteles informativos a ambos lados del puente. Ordenar e integrar en el entorno inmediato los pasos peatonales, el trazado del Arroyo de San Román, el trazado de la carretera y el camino del merendero de vías ciclistas, realizando una intervención sutil no agresiva con el paisaje ni con el propio acueducto. Plantación en los taludes de especies vegetales aromáticas del entorno. 


\section{Conclusiones}

Actualmente se ha intervenido en todos los pontones y en uno de los acueductos. Cada intervención ha sido realizada por un equipo especializado siguiendo pautas similares para el entendimiento de cada bien dentro del conjunto de construcciones del canal. Se ha pretendido hacer entendible su función, recuperando parte del trazado de los caminos o del canal en cada caso. Se han jalonado de pequeñas zonas estanciales y carteles explicativos que siguen el mismo grafismo. Sin embargo, la falta de mantenimiento, ha comenzado a devolver a los monumentos al punto de partida: la vegetación vuelve a engullirlos y la humedad y la suciedad hacen mella. Está claro que el patrimonio histórico es un valor que aporta riqueza a través del turismo. Pero no sólo es eso. También es parte de la historia del lugar, y es por ello que hay que educar desde la infancia a los propios vecinos y ciudadanos a quererlo como suyo y a hacerlo suyo y parte de su vida. Si no es así sin duda el canal y estas construcciones no tienen un buen futuro por delante.

\section{Referencias}

AA.VV. (1880). Caja 46-AH. Archivo del Canal de Isabel II.

Ministerio de Cultura y Deporte. (2007). Paisaje industrial del Pontón de la Oliva. Bienes Culturales, 7, 152-156. Madrid: IPHE.

Candela, P. (2009). Más que agua y piedra: el patrimonio histórico del Canal de Isabel II. Madrid: Canal Educa.

Espinosa, J. (2001). 1851: la creación del Canal de Isabel II. Madrid: Fundación del Canal de Isabel II.

López, A. (1986). La presa y el canal del Guadarrama al Guadalquivir y al océano, una utopía fallida del siglo XVIII. Boletín de la Real Academia de la Historia, Tomo 186, Cuaderno 2.

López, A. (1995). El canal de Cabarrús en el río Lozoya y los decretos de 1824 y 1829 sobre conducción de aguas a Madrid: las diversas propuestas. Estudios geográficos, Madrid.

López-Muñiz, G. (2015). Estudio histórico documental del Canal de Cabarrús. Madrid: Subdirección general de Patrimonio histórico de la Comunidad de Madrid.

Martín, P., y Prieto, F. (1988). Carlos III en la Comunidad de Madrid, arquitectura y obra civil en el medio rural. Madrid: Dirección General de Arquitectura.

Orduña, C. (1925). Los primeros estudios y las primeras obras del Canal de Isabel II. Revista de obras públicas, 2420, 2-5.

Verges, V. (2008). Illustrated glossary on stone deterioration patterns. Champigny/Marne: ICOMOS-ISCS. 